\title{
Relationship of Waist Circumference with Lipid and Glucose Metabolism among Southern Brazilian Children
}

\author{
Benini D. ${ }^{1}$, Possa G. ${ }^{2}$, Artifon M. ${ }^{3}$, Boscaini C. ${ }^{4}$, Pellanda L. ${ }^{4,5}$ \\ ${ }^{1 .}$ Universidade do Vale do Rio dos Sinos; \\ 2. Universidade Federal de São Paulo - UNIFESP; \\ ${ }^{3 .}$ Universidade Federal do Rio Grande do Sul - UFRGS; \\ 4. Instituto de Cardiologia / Fundação Universitária de Cardiologia; \\ ${ }^{5}$ Universidade Federal de Ciências da Saúde de Porto Alegre.
}

\begin{abstract}
Background and Aims: The measurement of waist circumference (wc) has been considered an important tool for identifying children at risk of metabolic and cardiovascular complications. To evaluate the relationship between WC and lipid and glucose metabolism.

Methods and Results: Cross-sectional study performed with a population-based sample of 588 children. Abdominal obesity was defined as WC above 90 percentile. The biochemical parameters evaluated were the serum levels involved in lipid and glucose metabolism. Children with high DC showed significantly higher prevalence of hypercholesterolemia $(49.2 \%$ v. $39.6 \% \quad p=0.022)$, hypertriglyceridemia $(39.0 \%$ v. $8.0 \%$ $p=<0.001)$, hyperinsulinemia $(10.2 \%$ v. $0.6 \% p=<0.001)$, insulin resistance $(27.1 \% v .2 .3 \% p=0.001)$ and inadequate levels of HDL-C $(53.4 \%$ v. $32.4 \% p=0.001)$. There were significant correlations between CC and insulin $(r=0.50)$, HOMA-IR (r=0.51), weight $(r=0.86)$, height $(r=0.53)$ and BMI $(r=0.87)(p<0.001)$. Conclusion: The results demonstrate the importance of measuring the CC to identify children at high risk of cardiovascular and metabolic changes.
\end{abstract}

Keywords: Waist circumference, abdominal obesity, children, nutritional and metabolic diseases

\section{Introduction}

In the last decades, a significant increase in the prevalence of overweight children was observed. In Brazil, a national inquiry showed an increase of $300 \%$ of obesity in 5 and 9 years-old children (Brasil, 2010). Waist circumference (WC) is considered a good indicator of central obesity and is established as a simple and effective measure (Burton, 2010). It constitutes one of the criteria for metabolic syndrome (MS) and its measurement might help identifying children with higher risk of developing chronicle diseases, being employed as an additional measure and as an isolated marker of cardiovascular risk also for children and teenagers (Han \& Lean, 2011; Ma et al., 2010). Children presenting elevated WC (above the 90th percentile) not only show a larger amount of visceral and subcutaneous fat, but are also exposed to an increased risk of developing dyslipidemia and insulin resistance (IR) (Bassali, Waller, Gower, Allison, \& Davis, 2010). Thus, identifying children with central obesity is critically important to prevent these conditions throughout life. However, the association of WC with lipid and glucose metabolism in young children is not yet very clear in medical literature. Therefore, the purpose of this study was to evaluate the relationship of central obesity, through the measurement of WC, with lipid and glucose metabolism in a population-based sample of children from 6 to 10 years-old.

\section{Methods}

Data from the study "Assessment of feeding practices, cardiovascular risk factors and inflammatory markers in children from state schools of the city of Garibaldi - RS" were used for this work. It is a populationbased cross-sectional study performed between 2011 and 2012 with a representative sample of the children from 6 to 10 years-old enrolled in public schools in the city of Garibaldi, Rio Grande do Sul. Children with mental disorders using medication that could interfere in the results of the study, those whose parents refused to sign the Informed Consent Form (ICF) and those studying in the rural area of the city were excluded.

The sample size was calculated with the aid of the EPI INFO software (Statcalc) and comprised 482 children. The calculation was made from a prevalence estimate of $38.7 \%$ of WC higher than the 90th percentile, as noted in the study of Hirschler, Aranda, Calcagno, Maccalini, and Jadzinsky (2005) with a level of confidence of $95 \%$ and margin of error of $4 \%$. The random selection of the schools was made based on the estimate of the average amount of enrolled students per school, and 13 from the 21 public schools in the urban area were included in the study. The total number of students enrolled in these schools was 1,464. 
Before data collection, a meeting was held with the individuals responsible for the children, in each school, with the purpose of presenting the study procedures, especially those related to the biochemical test (proper fasting and further care), distributing the ICF and scheduling the data collection and testing with children whose parents agreed to join the study.

Data collection took place in a clinical analysis laboratory located in the central area of the city, after blood was collected for the biochemical tests. The data collection team, comprised of a nutritionist and graduation Nutrition students previously enabled, made the interview, using a standard and pre-coded questionnaire containing data about age, gender, race, presence of clinical disease, family structure and income, which was divided in income quartiles for analysis purposes.

Weight and height data were measured in duplicate with the individual barefooted and wearing light clothing (shorts for boys and t-shirts for girls). For weight and height measuring, a digital scale (Techline®) with a $100 \mathrm{~g}$ variation and a stadiometer with $0.1 \mathrm{~cm}$ precision fixed in a flat wall were used, respectively. Children were placed vertically, erect, with parallel feet and with ankles, shoulders and buttocks touching the wall (Brasil, 2009). As an indicator of the nutritional state, it was used the body mass index (BMI), calculated through the ratio between the body mass and the squared height. For classifying the nutritional state, the cut-off points proposed by World Health Organization (WHO) were used: low BMI for the age (<score-z -2 ), proper or eutrophic BMI ( $\geq$ score-z -2 and $<$ score- $z+1)$, overweight $(\geq$ score- $z+1$ and $<$ score- $z+2)$ and obesity $(\geq$ score- $z$ +2 ) (World Health Organization, 2007). Parents of children presenting nutritional diagnosis of overweight or underweight were advised on the need of looking for specialized care.

In order to get the WC measure, the children were oriented to stand upright, with the abdomen relaxed and their arms loosen along the body. The tape measure was positioned in such a way to go around the waist, in the midpoint between the last rib and the iliac crest, firmly, but with no compression of the skin. Measure reading was obtained in the moment of expiration (Callaway et al., 1988). It was used a Cescorf ${ }^{\circledR}$ brand flexible inelastic fiber tape measure, with a $1 \mathrm{~mm}$ precision. The percentile distribution used for rating the $\mathrm{WC}$ was the one developed by Fernandez, Redden, Pietrobelli, and Allison (2004), which established as high WC values above the 90th percentile.

Blood (approximately $6 \mathrm{ml}$ ) was collected through venipuncture in the cubital fossa (in the elbow) using disposable material. The blood samples remained stored in vacutainer heparinized tubes, under a temperature of $-20^{\circ} \mathrm{C}$. The blood sampling followed the protocol established by the Brazilian Society of Cardiology (Giuliano et al., 2005) and was carried out always by the same biochemist, in the morning and after confirmation of proper fasting. The material remained stored according the provisions of the Ministry of Health and all the children were accompanied by their parents or guardians. The enzymatic/automated method was used in the analysis of serum TC, TG and glucose dosages. HDL-C was assessed using the direct/automated homogeneous method and insulin was assessed through chemiluminescence. LDL-C was calculated through the Friedewald formula (Friedewald, Lev, \& Fredrickson, 1972; Sposito et al., 2005).

For classification the lipid levels, the reference values suggested by the I Guideline for prevention of atherosclerosis in childhood and adolescence (Giuliano et al., 2005) for children and teenagers from 2 to 19 years-old, which recommends adopting the desirable values for TC $<150 \mathrm{mg} / \mathrm{dl}$, HDL-C $\geq 45 \mathrm{mg} / \mathrm{dl}$, LDL-C and TG $<100 \mathrm{mg} / \mathrm{dl}$. The limit values were considered normal, being: TC between $150 \mathrm{nd} 169 \mathrm{mg} / \mathrm{dl}$ and for LDL-C and TG between 100 and $129 \mathrm{mg} / \mathrm{dl}$. Values increased and/or considered inadequate were TC $>170 \mathrm{mg} / \mathrm{dl}$, HDL-C $<45 \mathrm{mg} / \mathrm{dl}$, LDL-C and TG $>130 \mathrm{mg} / \mathrm{dl}$. Classification of blood glucose under fasting was established based on the references mentioned by the Nutrology Scientific Department of the Brazilian Society of Pediatrics, which considers adequate blood glucose under fasting $<100 \mathrm{mg} / \mathrm{dl}$ (Sociedade Brasileira de Pediatria, 2012). Regarding the assessment of plasma insulin under fasting, the values described in the I Guideline for prevention of Atherosclerosis in Childhood and Adolescence. This classification considers the normal values of $<15 \mathrm{mU} / \mathrm{I}$, limits between 15 to $20 \mathrm{mU} / \mathrm{I}$ and high $>20 \mathrm{mU} / \mathrm{l}$ (Giuliano et al., 2005). The cut-off point of 2,5 (Madeira et al., 2008) was used to classify the HOMA-IR index. The results of the biochemical tests were made available for all parents and guardians and a letter was sent for those whose children presented any alteration, through mail or through school.

The data collected were submitted to double typing and validated in the software Epi-Info version 6.4 (CDC, Atlanta, USA). Quantitative variables were described through mean and standard deviation or median and interquartile range, and qualitative variables through absolute and relative frequencies. The t-Student test was used to compare the means between both groups. For more than two groups, the one-way analysis of variance (ANOVA) post-hoc of Tukey was applied. In case of asimmetry, the Mann-Whitney or Kruskal-Wallis tests were used. The Pearson's Chi-square or Fisher's exact tests were applied in the association between categorical variables. The adopted significance level was $5 \%(\mathrm{p} \leq 0,05)$ and the analysis were carried out in the SPSS (Statistical Package for the Social Sciences) software, version 17.0. The Pearson correlation test was applied in the analysis of association between continuous variables. 
The main study was submitted to the evaluation of the Research Ethics Committee of the Cardiology Institute - University Foundation of Cardiology and was approved. In addition, there was the acceptance by the City Hall of Garibaldi and the Secretaries of Education and Health, with the signature of the knowledge letter of the study. After this, the contact with the principals was made and the project was presented in the schools. The study was founded by the City Hall of Garibaldi, through the City Secretary of Health.

\section{Results}

Of the 588 children evaluated, $51 \%$ were male with an mean age of 8,61+1,36. Table 1 presents the sociodemographic characteristics of the studied population. Overweight and central obesity total prevalences were $37,4 \%$ and $10,5 \%$, respectively. Table 2 presents characterization of the nutritional state and the WC of the children assessed, according to gender. No significant differences were found between genders for these variables $(\mathrm{p}=0.748$ and $\mathrm{p}=0.810)$.

Characterization of WC and its relation to the metabolic profile of the children on the study is presented on table 3. Children with high WC presented greater prevalence of inadequate levels of TC (49,2\% v. 39,5\% $\mathrm{p}=0,022)$, TG $(39,0 \%$ v. $8,0 \% \mathrm{p}=<0,001)$, insulin $(10,2 \%$ v. $0,6 \% \mathrm{p}=<0,001)$, HOMA-IR $(27,1 \%$ v. $2,3 \%$ $\mathrm{p}=0,001)$ and lower HDL-C $(53,4 \%$ v. $32,4 \% \mathrm{p}=0,001)$. The correlations of WC with studied variables are presented in table 4. There were significant direct correlations between $\mathrm{WC}$ and insulin $(r=0,50 ; p<0,000)$, HOMA-IR ( $r=0,51 ; p<0,000)$, weight $(r=0,86 ; p<0,000)$, height $(r=0,53 ; p<0,000)$ and BMI $(r=0,87 ; p<0,001)$. Weak, but significant, correlations of the variables HDL-C, TG and glucose were observed.

\section{Discussion}

The results in this cross-sectional study showed that the children with high WC presented higher TC, TG, insulin, HOMA-IR and lower HDL-C serum levels, regardless of gender, and these values are statistically significant. These findings are consistent with the initial hypothesis that there is a relation between WC and lipid and insulin metabolism. Furthermore, this study found strong and important correlations between WC and the variables insulin, HOMA-IR, weight, height and BMI. Therefore, the children with WC above 90 percentile have a higher probability of presenting IR and overweight or obesity. There is already evidence of some of these associations in adults (Fahim, Christine, \& Gerald, 2013), however, there are few studies among young children investigating the same variables and their correlations with WC.

The role of abdominal fat in the development of diseases has been increasingly recognized, and there is a clear connection between abdominal fat and metabolic changes, such as high levels of serum cholesterol, TG and high concentrations of insulin. Works published in the literature analyzing children in the same age group had similar results (Freedman, Serdula, Srinivasan, \& Berenson, 1999; Hirschler et al., 2005; Mager et al., 2013; Moreira et al., 2008; Ruiz et al., 2007). The Bogalusa Heart Study (Freedman et al., 1999), with approximately 3,000 children and adolescents between 5 and 7 years-old found a positive association of the WC with high serum levels of TG and insulin, as well as low rates of HDL-C. Another study, in 2005 (Hirschler et al., 2005), investigated whether WC could identify children with MS, and observed the relation of this measure with high levels of LDL-C, TG and HOMA-IR index.

Both studies aforementioned considered the $90^{\text {th }}$ percentile as the indicator of central obesity, however, WC measurement in the latter was carried out in the line of the umbilical scar, which proves the fact that there is not, until this moment, an international standard for cut-off points for classifying central adiposity peculiar to children. Therefore, it use as an impacting tool in public health advisory has been limited. It is necessary, for children and adolescents, the use of specific cut-off points of WC by gender and age, given that this age group shows significant variations due to the intense growth and development process (Liu et al., 2010).

Despite the recognized importance of measuring the WC in relation to metabolic changes, there are no international references of this variable for children available until the present moment. Several countries, including the United Kingdom (McCarthy, Ellis, \& Col, 2003; McCarthy, Jarrett, \& Crawley, 2001), Germany (Schwandt, Kelishadi, \& Haas, 2008), Italy (Zannolli \& Morgese, 1996), Australia (Eisenmann, 2005), USA (Fernandez et al., 2004), Canada (Katzmarzyk, 2004), and Mexico (Gómez-Díaz et al., 2005) have published national references for different age groups. Brazil does not have references, especially for children age groups, and furthermore there are still few studies using these correlations for measuring WC in children.

Due to the increasing importance of obesity and risk factors (RF) for cardiovascular diseases (CVD) amongst children and adolescents, there is an interest in investigating the presence of metabolic changes similar to those found in adult MS. The increase of body fat, especially visceral, is associated to chronic diseases, such as diabetes mellitus, dyslipidemia and high blood pressure. Visceral fat has a larger lipolitic function compared to subcutaneous fat, issuing a larger amount of free fat acids and glycerol, which are directed to the liver, starting a series of changes in lipid metabolism. In addition, adipose tissue has a prominent role in IR pathogenesis due to the liberation of metabolites and hormones that affect different stages of insulin action (Chiarelli \& Marcovecchio, 2008). 
Despite the difficulty to establish the diagnosis of these RFs, it is critical to stress the importance of identifying children and adolescents that meet the requirements for this diagnosis, as they have higher metabolic risk and must be properly followed up. Continuity of these changes may favor the development of diabetes mellitus type 2 and occurence of CVD in adult life (Cavali, Escrivão, Brasileiro, \& Taddei, 2010).

This study presents some limitations: 1) The biochemical data may have suffered changes due to inadequate fasting period of the children, even with previous guidance to parents and guardians; 2) the measurement of WC was standardized through training provided to interviewers, however it is known that this measuring is delicate and demands some sensitivity and experience to find the correct spot; 3) it was not possible to identify IR by euglycemic clamp, which is considered the gold standard and that might have influenced the results.

\section{Conclusion}

The results of this study indicate that the excess of adipose tissue in the abdominal region of children was associated with higher lipid, insulin and IR levels, in addition to showing a strong correlation with insulin, HOMA-IR, weight, height and BMI. Therefore, measurement of WC can be considered an important tool for identifying children at higher risk of developing metabolic and cardiovascular complications.

In Brazil there is a need of more works investigating the association of metabolic markers with overweight, more specifically with central obesity in children. Furthermore, lack of methodological standardization of WC measure demands caution when comparing results from different studies. It is suggested carrying out new studies assessing a cut-off point for classifying WC in children, the same way as with adults.

\section{References}

[1]. Bassali, R., Waller, J. L., Gower, B., Allison, J., Davis, C. L. (2010). Utility of waist circumference percentile for risk evaluation in obese children. International Journal of Pediatric Obesity, 5(1), 97-101.

[2]. Brasil. Ministério da Saúde. Secretaria de Atenção à Saúde. (2009). Cadernos de Atenção Básica. Saúde na Escola n 24. Brasília, DF: Ministério da Saúde.

[3]. Brasil. Ministério do Planejamento, Orçamento e Gestão. Instituto Brasileiro de Geografia e Estatística. (2010). Pesquisa de orçamentos familiares 2008-2009: antropometria e estado nutricional de crianças, adolescentes e adultos no Brasil. Rio de Janeiro, RJ: IBGE.

[4]. Burton, R. F. (2010). Waist circumference as an indicator of adiposity and the relevance of body height. Medical Hypotheses, 75:(1), 115-119.

[5]. Callaway, C. W., Chumlea, W. C., Bouchard, C., Himes, J. H., Lohman, T. G., Martin, A. D, ... Martorell, R. (1988) Anthropometric standardization reference manual. Illinois, IL: Human Kinetics.

[6]. Cavali, M. L., Escrivão, M. A., Brasileiro, R. S., Taddei, J. A. (2010). Metabolic syndrome: comparison of diagnosis criteria. Jornal de Pediatria (Rio J), 86(4), 325-330.

[7]. Chiarelli, F., Marcovecchio, M. L. (2008). Insulin resistance and obesity in childhood. European Journal of Endocrinology, 159 Suppl. 1, 67-74.

[8]. Eisenmann, J. C. (2005). Waist circumference percentiles for 7- to 15-year-old Australian children. Acta Paediatrica, 94(9), 11821185 .

[9]. Fahim, A., Christine, B., Gerald, M. R. (2013). Cardiometabolic risk factors and obesity: does it matter whether BMI or waist circumference is the index of obesity? The American Journal of Clinical Nutrition, 98(3), 637-640.

[10]. Fernandez, J. R., Redden, D. T., Pietrobelli, A., Allison, D. B. (2004). Waist circumference percentiles in nationally representative simples of African- American, European-American, and Mexican-American children and adolescents. The Journal of Pediatrics, 145(4), 439-444.

[11]. Freedman, D. S., Serdula, M. K., Srinivasan, S. R., Berenson, G. S. (1999). Relation of circumferences and skinfold thicknesses to lipid and insulin concentrations in children and adolescents: the Bogalusa Heart Study. The American Journal of Clinical Nutrition, 69(2), 308-317.

[12]. Friedewald, W. T., Lev, R. I., Fredrickson, D. S. (1972). Estimation of the concentration of low-density lipoprotein cholesterol in plasma, without use of the preparative ultracentrifuge. Clinical Chemistry, 18(6), 499-502.

[13]. Giuliano, I. C. B., Caramelli, B., Pellanda, L. C., Duncan, B., Mattos, S., Fonseca, F. H. (2005). I Diretriz de Prevenção da Aterosclerose na Infância e na Adolescência. Arquivos Brasileiros de Cardiologia, 85 Suppl. 6, 10-19.

[14]. Gómez-Díaz, R. A., Martínez-Hernández, A. J., Aguilar-Salinas, C. A., Violante, R., Alarcón, M. L., Villarruel, M. J., ... SolórzanoSantos, F. (2005). Percentile distribution of the waist circumference among Mexican preadolescents of a primary school in Mexico City. Diabetes, Obesity \& Metabolism, 7(6), 716-721.

[15]. Han, T. S., Lean, M. E. J. (2011). Metabolic syndrome. Medicine, 39, 24-31.

[16]. Hirschler, V., Aranda, C., Calcagno, M. L., Maccalini, G., Jadzinsky, M. (2005). Can Waist Circumference Identify Children With the Metabolic Syndrome? Archives of pediatrics \& adolescent medicine, 159(8), 740-744.

[17]. Katzmarzyk, P. T. (2004). Waist circumference percentiles for Canadian youth 11-18 y of age. European Journal of Clinical Nutrition, 58(7), 1011-1015.

[18]. Liu, A., Hills, A. P., Hu, X., Li, Y., Du, L., Xu, Y., ... Ma, G. (2010). Waist circumference cut-off values for the prediction of cardiovascular risk factors clustering in Chinece school-aged children: a cross-sectional study. BMC Public Health, $10,82$.

[19]. Ma, G. S., Ji, C.Y., Ma, J., Mi, J., Yt, Sung R., Xiong, F., ... Jiang, J. X. (2010). Waist circumference reference values for screening cardiovascular risk factors in Chinese children and adolescents. Biomedical and Environmental Sciences, 23, (1), 21-31.

[20]. Madeira, I. R., Carvalho, C. N., Gazolla, F. M., de Matos, H. J., Borges, M. A., Bordallo, M. A. (2008). [Cut-off point for Homeostatic Model Assessment for Insulin Resistance (HOMA-IR) index established from Receiver Operating Characteristic (ROC) curve in the detection of metabolic syndrome in overweight pre-pubertal children]. Arquivos Brasileiros de Endocrinologia e Metabologia, 52(9), 1466-1473. [Article in Portuguese]. 
[21]. Mager, D. R., Yap, J., Rodriguez-Dimitrescu, C., Mazurak, V., Ball, G., Gilmour, S. (2013). Anthropometric Measures of Visceral and Subcutaneous Fat Are Important in the Determination of Metabolic Dysregulation in Boys and Girls at Risk for Nonalcoholic Fatty Liver Disease. Nutrition in Clinical Practice, 28(1), 101-111.

[22]. McCarthy, H. D., Ellis, S. M., Cole, T. J. (2003). Central overweight and obesity in British youth aged 11-16 years: cross sectional surveys of waist circumference. BMJ, 326(7390), 624.

[23]. McCarthy, H. D., Jarrett, K. V., Crawley, H. F. (2001). The development of waist circumference percentiles in British children aged 5.0-16.9 y. European Journal of Clinical Nutrition, 55(10), 902-907.

[24]. Moreira, S. R., Ferreira, A. P., Lima, R. M., Arsa, G., Campbell, C. S., Simões, H. G., ... França, N. M. (2008). Predicting insulin resistance in children: anthropometric and metabolic indicators. Jornal de Pediatria (Rio J), 84(1), 47-52.

[25]. Ruiz, J. R., Rizzo, N. S., Ortega, F. B., Loit, H. M., Veidebaum, T., Sjöström, M. (2007). Markers of insulin resistance are associated with fatness and fitness in school-aged children: the European Youth Heart Study. Diabetology, 50(7), 1401-1408.

[26]. Schwandt, P., Kelishadi, R., Haas, G. M. (2008). First reference curves of waist circumference for German children in comparison to international values: the PEP Family Heart Study. World Journal of Pediatrics, 4(4), 259-266.

[27]. Sociedade Brasileira de Pediatria. (2012). Obesidade na infância e adolescência: manual de orientação. São Paulo, SP: SBP.

[28]. Sposito, A. C., Caramelli, B., Fonseca, F. A., Bertolami, M. C., Afiune Neto, A., Souza, A. D., ... Sociedade Brasileira de Cardiologia. (2007). [IV Brazilian Guideline for Dyslipidemia and Atherosclerosis prevention: Department of Atherosclerosis of Brazilian Society of Cardiology]. Arquivos Brasileiros de Cardiologia, 88 Suppl. 1, 2-19. [Article in Portuguese]

[29]. World Health Organization. (2007). Growth reference data for 5-19 years. Geneva, WHO.

[30]. Zannolli, R., Morgese, G. (1996). Waist percentiles: a simple test for atherogenic disease? Acta Paediatrica, 85(11), 1368-1369.

\section{TABLES}

Table 1. Sociodemographic characteristics of students in Southern Brazil ( $\mathrm{n}=588)$.

\begin{tabular}{|l|l|l|l|}
\hline Variable & n & mean+SD & \% \\
\hline Age & & $8.61 \pm 1.36$ & \\
\hline Gender & & & \\
\hline Female & 286 & & 49 \\
\hline Male & 302 & & 51 \\
\hline Race & & & 86 \\
\hline Caucasian & 505 & & 14 \\
\hline Other & 83 & & \\
\hline Clinical disease & & & 13 \\
\hline Yes & 79 & & 87 \\
\hline No & 509 & & 74 \\
\hline Family structure & & & 26 \\
\hline Nuclear* & 436 & & \\
\hline Non-nuclear & 152 & & 24 \\
\hline Family income (R\$) & & & 24 \\
\hline Quartile I (<1,700.00) & 142 & & 27 \\
\hline Quartile II (1,700.00 to 2,200.00) & 142 & & 25 \\
\hline Quartile III (2,200.00 to 3,000.00) & 157 & & \\
\hline Quartile IV (<3,000.00) & 147 & & \\
\hline
\end{tabular}

* Nuclear family structure - child lives only with parents.

Table 2. Characterization of nutritional condition and waist circumference according to gender among students in Southern Brazil $(\mathrm{n}=588)$.

\begin{tabular}{|c|c|c|c|c|c|c|c|c|}
\hline \multirow[t]{2}{*}{ Variable } & Low Weight & Eutrophia & Overweight & Obesity & \multirow[t]{2}{*}{$\mathbf{p}$} & High WC & Adequate WC & \multirow[t]{2}{*}{$\mathbf{p}$} \\
\hline & n (\%) & n (\%) & n(\%) & n (\%) & & n (\%) & n $(\%)$ & \\
\hline Age (mean+SD) & $8.63 \pm 1.62$ & $8.60 \pm 1.33$ & $8.75 \pm 1.40$ & $8.48 \pm 1.38$ & $0.519 *$ & $8.63 \pm 1.42$ & $8 . .61 \pm 1.36$ & $0.916^{\S}$ \\
\hline Gender & & & & & $0.748^{\dagger}$ & & & $0.810^{\dagger}$ \\
\hline Female & $4(1,4)$ & $173(60.5)$ & $61(21.3)$ & $48(16.8)$ & & $31(11.0)$ & $252(89.0)$ & \\
\hline Male & $8(2.6)$ & $183(60.6)$ & $61(20.2)$ & $50(16.6)$ & & $30(10.0)$ & $270(90.0)$ & \\
\hline Total & $12(2.0)$ & $356(60.5)$ & $122(20.7)$ & $98(16.7)$ & & $61(10.5)$ & $522(89.5)$ & \\
\hline
\end{tabular}

WC - Waist circumference; *one -way Analysis of Variance (ANOVA) post-hoc of Tukey; Pearson

Chi-square test; ${ }^{\S}$ t-Student Test.

Table 3. Waist circumference and serum levels of insulin, glucose and lipid profile among students in Southern Brazil $(n=588)$.

\begin{tabular}{|c|l|l|l|l|l|}
\hline Variable* & High WC & mean+SD & Adequate WC & mean+SD & p \\
\cline { 2 - 4 } & $\mathbf{n}(\%)$ & & & \\
\hline Total Cholesterol & & $173.7 \pm 30.0(\mathrm{n}=59)$ & & $165.2 \pm 26.2(\mathrm{n}=515)$ & $\mathbf{0 . 0 2 2}^{\dagger}$ \\
\hline$\geq 170 \mathrm{mg} / \mathrm{dl}$ & $29(49.2)$ & & $204(39,6)$ & & \\
\hline$<170 \mathrm{mg} / \mathrm{dl}$ & $30(50.8)$ & & $311(60.4)$ & & \\
\hline HDL-C & & $45.0 \pm 9.0(\mathrm{n}=58)$ & & $50.0 \pm 10.6(\mathrm{n}=512)$ & $\mathbf{0 . 0 0 1}^{\dagger}$ \\
\hline$\leq 45 \mathrm{mg} / \mathrm{dl}$ & $31(53.4)$ & & $166(32.4)$ & & \\
\hline$>45 \mathrm{mg} / \mathrm{dl}$ & $27(46.6)$ & & $346(67.6)$ & & $0.106^{\dagger}$ \\
\hline LDL-C & & $101.3 \pm 25.0(\mathrm{n}=58)$ & & $95.8 \pm 24.1(\mathrm{n}=512)$ \\
\hline$\geq 130 \mathrm{mg} / \mathrm{dl}$ & $8(13.8)$ & & $45(8.8)$ & & \\
\hline$<130 \mathrm{mg} / \mathrm{dl}$ & $50(86.2)$ & & $467(91.2)$ & & \\
\hline Triglycerides & & $130.2 \pm 56.9(\mathrm{n}=59)$ & & $94.1 \pm 25.7(\mathrm{n}=515)$ & $<\mathbf{0 , 0 0 1}$ \\
\hline
\end{tabular}


Relationship of Waist Circumference with Lipid and Glucose Metabolism among Southern Brazilian ..

\begin{tabular}{|l|l|l|l|l|l|}
\hline$\geq 130 \mathrm{ml} / \mathrm{dl}$ & $23(39.0)$ & & $41(8.0)$ & \\
\hline$<130 \mathrm{mg} / \mathrm{dl}$ & $36(61.0)$ & & $474(92.0)$ & & \\
\hline
\end{tabular}

Table 3 (continued)

\begin{tabular}{|c|c|c|c|c|c|}
\hline \multirow[t]{2}{*}{ Variable* } & High WC & \multirow[t]{2}{*}{ mean+SD } & Adequate WC & \multirow[t]{2}{*}{ mean+SD } & \multirow[t]{2}{*}{$\mathbf{p}$} \\
\hline & n (\%) & & n (\%) & & \\
\hline Insulin & & $9.3(6.4-13.9)(n=59)$ & & $4.7(3.1-6.3)(n=515)$ & $<0,001^{\S}$ \\
\hline$>20 \mathrm{mU} / 1$ & $6(10.2)$ & & $3(0.6)$ & & \\
\hline$<20 \mathrm{mU} / \mathrm{l}$ & $53(89.8)$ & & $512(99.4)$ & & \\
\hline Glucose & & $83.9 \pm 6.9(n=59)$ & & $82.7 \pm 7.3(n=515)$ & $0.246^{\dagger}$ \\
\hline$\geq 100 \mathrm{mg} / \mathrm{dl}$ & $1(1.7)$ & & $4(0.8)$ & & \\
\hline$<100 \mathrm{mg} / \mathrm{dl}$ & $58(98.3)$ & & $511(99.2)$ & & \\
\hline HOMA-IR & & $1.76(1.25-2.60)(n=59)$ & & $0.85(0.56-1.18)(\mathrm{n}=515)$ & $<0,001^{\S}$ \\
\hline$>2.5$ & $16(27.1)$ & & $12(2.3)$ & & \\
\hline$<2.5$ & $43(72.9)$ & & $503(97.7)$ & & \\
\hline
\end{tabular}

HDL - High density lipoprotein; LDL - Low density lipoprotein; HOMA-IR - Homeostatic model assessment of insulin resistance; WC - Waist circumference; *Variables described by mean $\pm S D$, median (percentile 25 - 75) or $n(\%)$; ${ }^{\dagger}$-Student test; ${ }^{\S}$ Mann-Whitney test.

Table 4. Correlation between waist circumference and biochemical and anthropometric variables among students in Southern Brazil $(\mathrm{n}=588)$.

\begin{tabular}{|l|l|l|}
\hline Variable & $\mathbf{r}$ & $\mathbf{p}$ \\
\hline Total Cholesterol & 0.06 & $0.100^{*}$ \\
\hline HDL-C & -0.08 & $\mathbf{0 . 0 4 1}$ \\
\hline LDL-C & 0.02 & $0.584^{*}$ \\
\hline Triglycerides & 0.31 & $<\mathbf{0 . 0 0 0}^{*}$ \\
\hline Insulin & 0.50 & $<\mathbf{0 . 0 0 0}^{*}$ \\
\hline Glucose & 0.13 & $<\mathbf{0 . 0 0 0}^{*}$ \\
\hline Homa - IR & 0.51 & $<\mathbf{0 . 0 0 0}^{*}$ \\
\hline Weight & 0.86 & $<\mathbf{0 . 0 0 0}^{*}$ \\
\hline Height & 0.53 & $<\mathbf{0 . 0 0 0}^{*}$ \\
\hline BMI & 0.87 & $<\mathbf{0 . 0 0 1}^{*}$ \\
\hline
\end{tabular}

* Pearson Correlation Test; HDL - High density lipoprotein; LDL - Low density lipoprotein; HOMA-IR Homeostatic model assessment of insulin resistance. 